\title{
Testicular stereological and histological changes in an experimental murine model of visceral leishmaniasis
}

\author{
Yarahmadi E ${ }^{1}$, Shalizar- Jalali $\mathbf{A}^{2}$, Jalallou $\mathbf{N}^{3}$, Shaddel $\mathbf{M}^{4}$ \\ 1. Doctor of Veterinary Medicine (DVM), Department of Parasitology, Faculty of Medicine, Aja University of Medical \\ Sciences, Tehran, Iran. ORCID ID: 0000-0001-7861-8458 \\ 2. Associate Professor of Histology, Department of Basic Sciences, Faculty of Veterinary Medicine, Urmia University. \\ Urmia, Iran. \\ 3. Assistant Professor of Parasitology, Department of Medical Laboratory Science, Faculty of Paramedicine, AJA University \\ of Medical Sciences, Tehran, Iran. \\ 4. Associate Professor of Parasitology, Department of Parasitology, Faculty of Medicine, Aja University of Medical \\ Sciences, Tehran, Iran (Corresponding author), Tel: +982143822906, Email: min_shad@yahoo.com, ORCID ID: 0000-0002 \\ 7820-3866
}

\begin{abstract}
Background and Aim: Visceral leishmaniasis, a native disease in developing countries, can cause functional impairment in various organs, including the reproductive system, which can lead to infertility. The aim of this study was to evaluate the stereological, morphometric and morphological changes of testicular histoarchitecture in an experimental murine model of visceral leishmaniasis in BALB/c mice.

Materials and Methods: In this experimental study, 20 adult male BALB/c mice were randomly divided into two equal groups including control and experimental (infected with visceral leishmaniasis) groups. In the experimental group, infection was induced by intraperitoneal injection of $0.2 \mathrm{ml}$ of a solution containing $12 \times 10^{6}$ promastigotes of Leishmania infantum in the stationary phase. 6 weeks after the start of the study, all the mice were euthanized after induction of anesthesia, then the spleens and testicles of the animals were removed immediately under sterile condition and examined for signs of infection and histological changes.

Results: The experimental group showed significant reductions in the diameter, germinal epithelium height, cross-sectional area, quality, maturation and number of seminiferous tubules as well as obvious testicular morphological changes including severe hypocellularity and spermatogenic cell maturation arrest in comparison to the control group.

Conclusion: The results indicated that visceral leishmaniasis in BALB/c mice may lead to testicular histological injuries because of incitement of inflammatory reactions, microcirculatory disruption, and involvement of the hematopoietic system.
\end{abstract}

Keywords: Histology, Mouse, Testis, Visceral leishmaniasis

Received: May 11, 2019

Accepted: August 17, 2019

How to cite the article: Yarahmadi E, Shalizar- Jalali A, Jalallou N, Shaddel M. Testicular stereological and histological changes in an experimental murine model of visceral leishmaniasis. SJKU 2019;24(4):86-94.

Copyright (C) 2019 the Author (s). Published by Kurdistan University of Medical Sciences. This is an open access article distributed under the terms of the Creative Commons Attribution-Non Commercial License 4.0 (CCBY-NC), where it is permissible to download, share, remix, transform, and buildup the work provided it is properly cited. The work cannot be used commercially without permission from the journal. 


\section{ارزيابى تغييرات استريولوزيك و بافتشناسى بيضه در مدل تجربى ليشمانيازيس احشايى در Bوشهاى BALB/c}

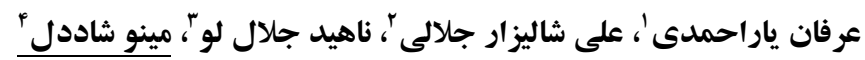

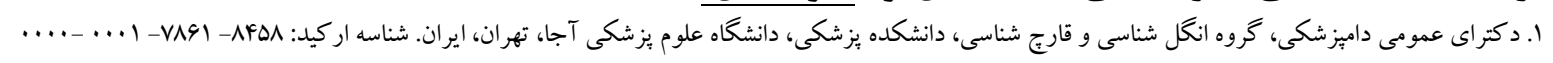

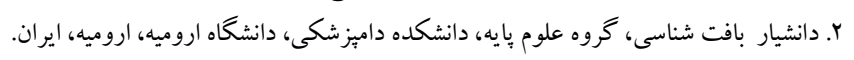

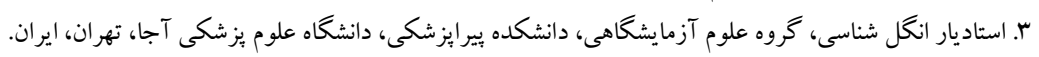

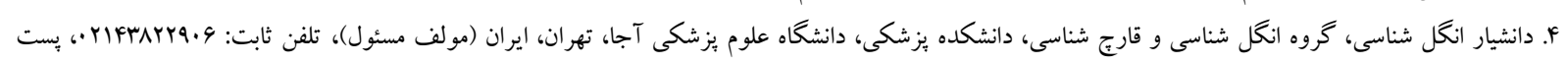

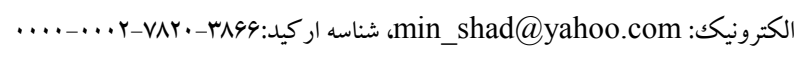

جكيده

زمينه وهدف: بيمارى ليشمانيوز احشايى به عنوان بيمارى بومى كشورهاى در حال توسعه، به واسطه ايجاد اختلال عملكردى در

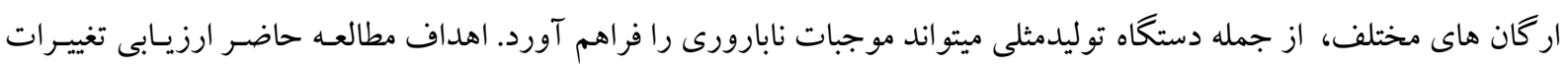

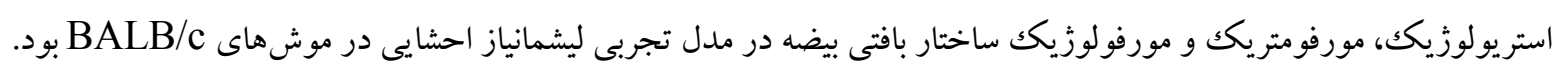
روش بررسى: در اين مطالعه تجربى، ·r موش نر بالغ BALB/c به صورت تصادفى به دو گروه مساوى شامل شاهد (فاقد تيمار)

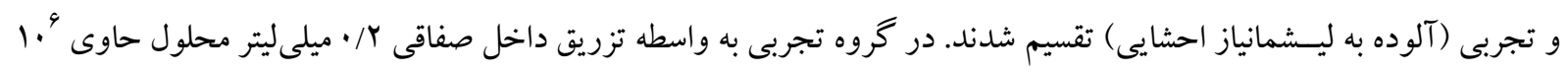

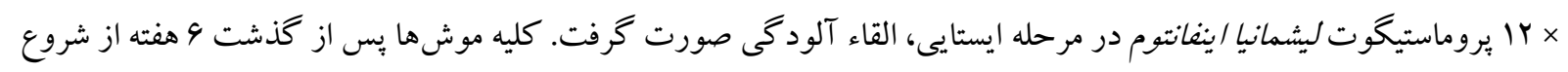

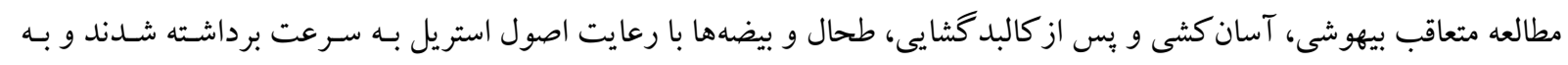

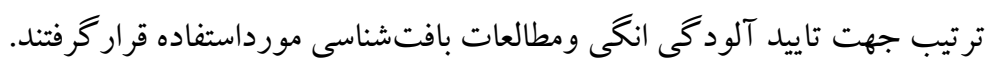

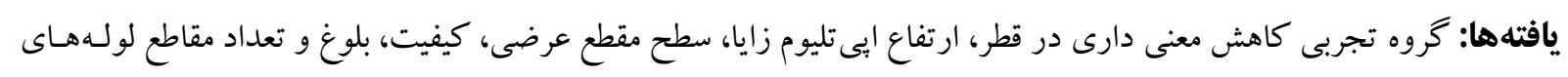

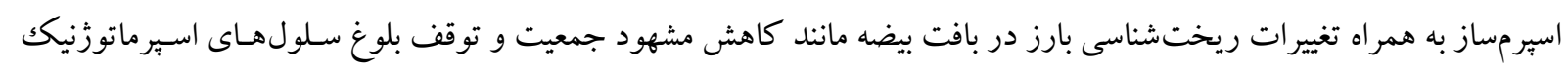
در مقايسه با گروه شاهد نشان داد.

نتيجه كيرى: يافتهاى مطالعه حاضر نشان داد كه ليسشمانياز احسشايى در موشهاى BALB/c ممكن است به به واسطه برانخيختن

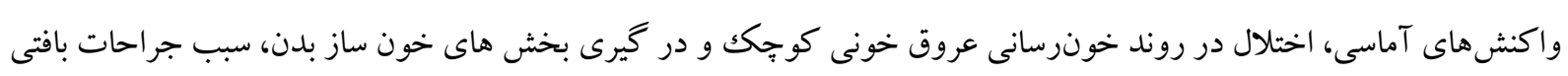
بيضه گردد.

كليدوازه ها: بافتشناسى، موش، بيضه، ليسشمانيازيس احسشايى وصول مقاله: IN/Y/r| 
تحقيقات انستيتو رازى كرج خريدارى تهيه گرديد. حيو انات

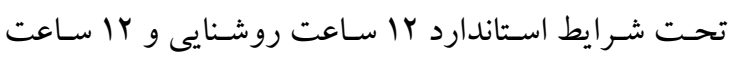

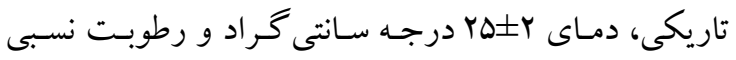

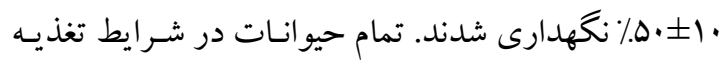

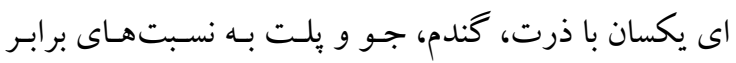

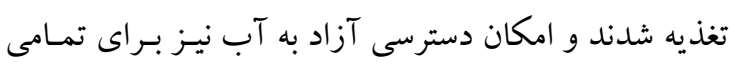

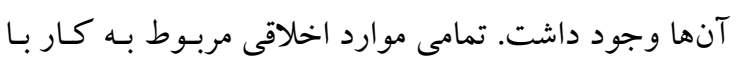

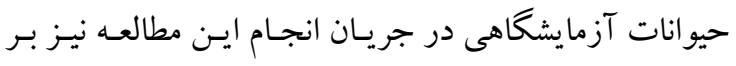

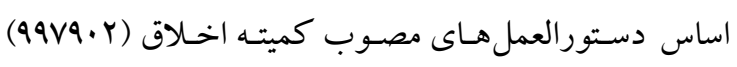

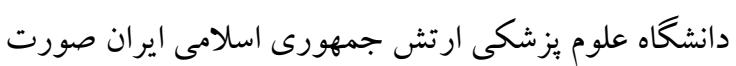

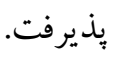

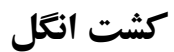
سويه استاندارد ليشمانيا /ينغانتوم از انستيتو باستور تهران تهيه

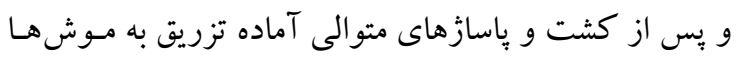
شد. بهمنظور كشت انغل، محيط

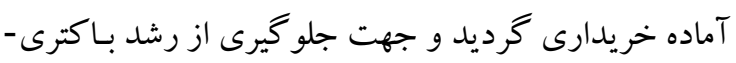

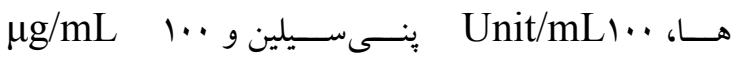

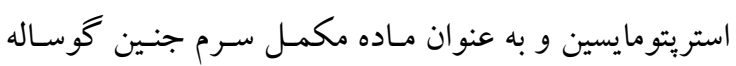

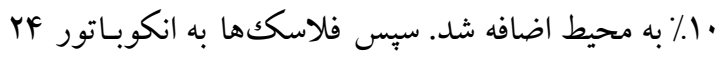
درجه سانتيخراد منتقل و هر روز با ميكروسكو

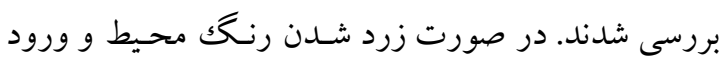

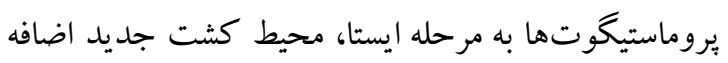

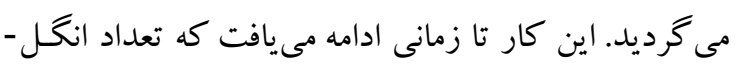
ها به ميزان مورد نياز برسد. براى شمارش تعداد انغلها نيز

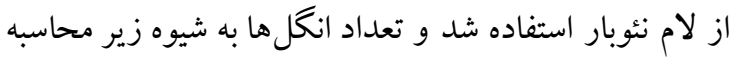

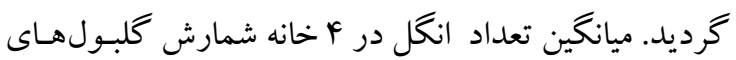

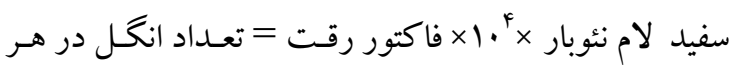

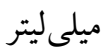
كروهبندى حيوانات متعاقب يكك هفته ساز كارى با شـر ايط محيط، حيوات انـات بـهـ صورت تصادفى به دو گروه مساوى •ا تايى تقسيم شـدند:

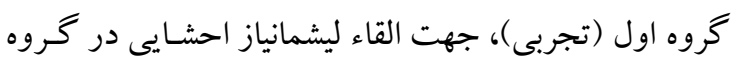
ليشمانياز احشايى تجربى، ب/ • ميلى ليتر محلول حاوى
مقدمه

ليـشمانياز احسشايى به عنوان يكى از مهمترين بيمـارىهاى

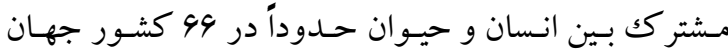

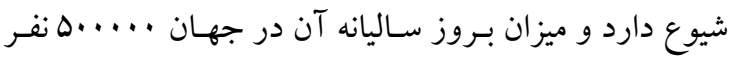
تخمين زده شده است (r-1). بررسىهاى اخيـر نيز آشكار

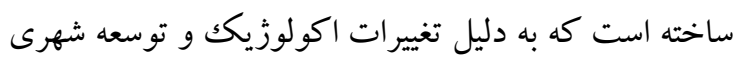

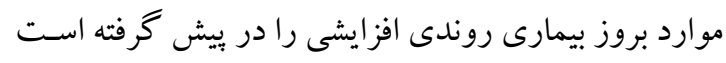

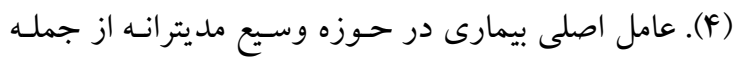

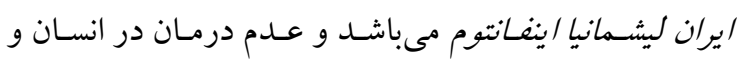

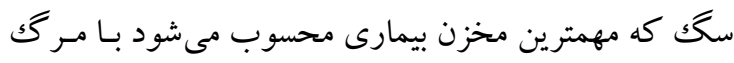

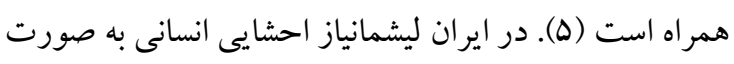

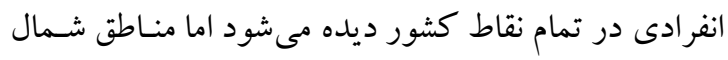

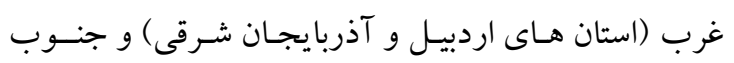

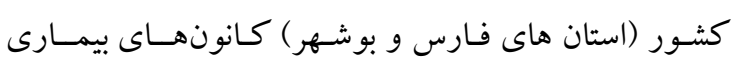
محسوب مى گردند (9). از سوى ديخر، با توجه به گزارشات

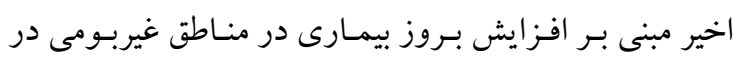

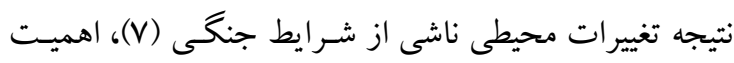

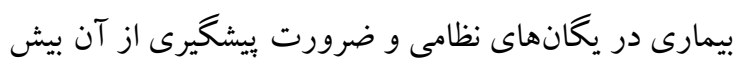
از بيش مدنظر قرار گرفته است (A). در همسين راسـتا، مطالعـات بيثـسيين نشـان داده اسـت كـهـ

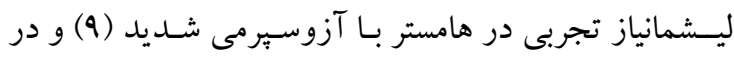

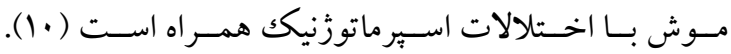

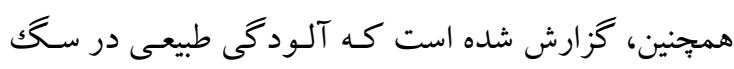
مى تواند آسيب بافت بيضه را در بي داشته باشد (11).

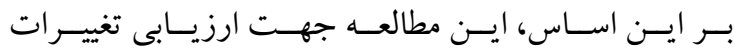

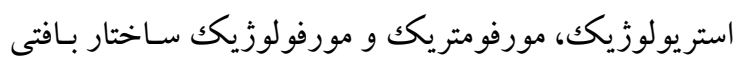

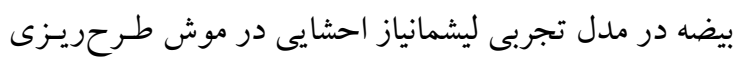
كرديد. - مان. آماده سازى حيوان بورسي

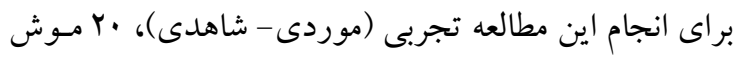

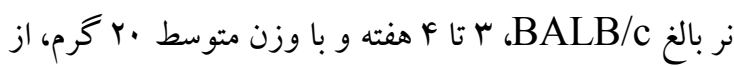

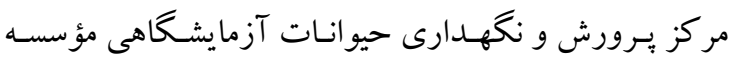


واحد سطح بيضه، D. ميانگين قطر لوله هاى اسبرمسـاز و T،

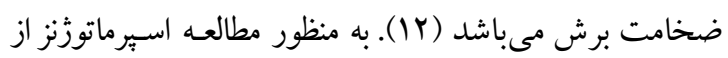

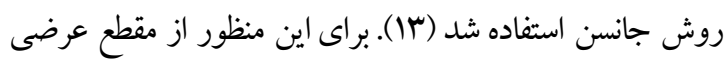

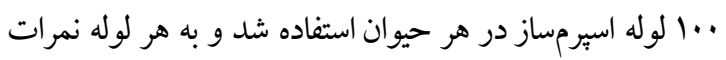

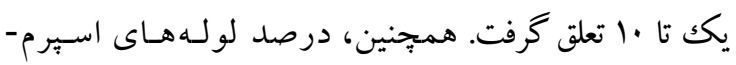
ساز با بلوغ بالا (نمرات و و · ل1) نيز مورد محاسبه قرار

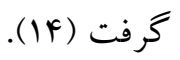
روش آمارى

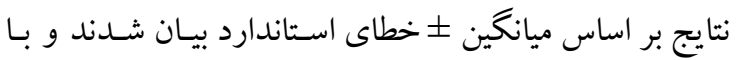

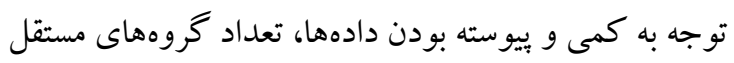

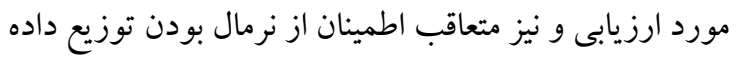

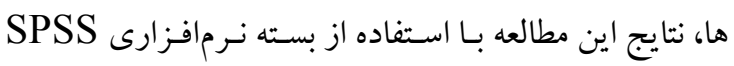

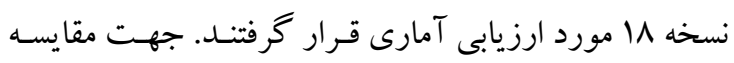

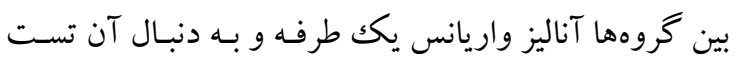

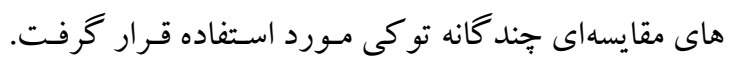
مقدار هـ/•>> pبر اي تعيين سطح معنىدارى بين گرووهها در نظر خرفته شد.

\section{يافتهها}

طبق بررسى آمارى نتـايج ارزيـابىهـاى هيستومورفومتريك ماكس

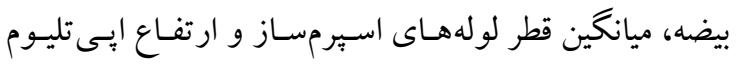

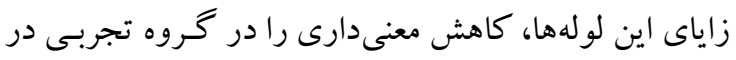

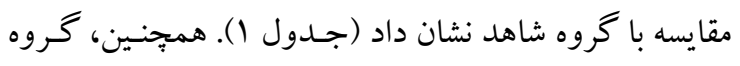

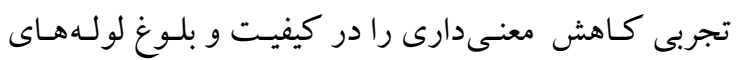
اسبرمساز بيضه در مقايسه با گروه شـاهد نشـان داد (جـدول

طبق بررسى هاى اسـتريولوزيك نيز، گحروه تجربى كاهش معنى دارى را در سطح مقطع عرضى لو لـهــاى اسبرمصـاز و

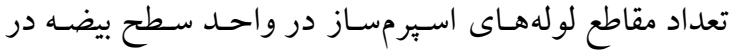

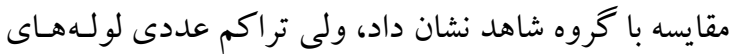

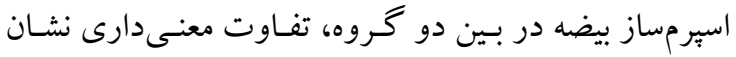

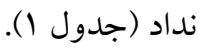

r ب بروماسـتيخوت ليشـمانيا /ينغانتوم در مرحلـه ايستايى بـه صورت داخل صفاقى تزريق گرديـد. گـروه دوم (شـاهد)،

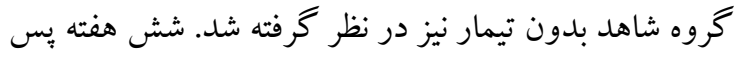
از شروع مطالعه، موشها متعاقب آسان كشى به واسطه تجويز

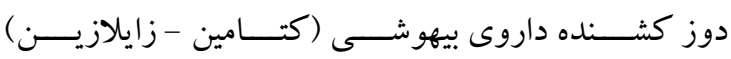
كالبد گشايى شدند و بيضهها و طحسال حيوانـات، بـا رعايـت اصول استريل به ترتيب جهت مطالعات بافتشناسى و تاييـد آلودگى انكى برداشته شدند.

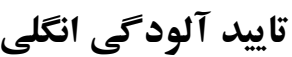

در بِايان دوره مطالعه، جهت الطمينان حاصل كردن از القـاى

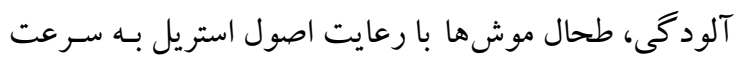

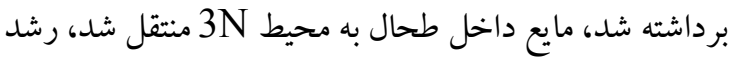

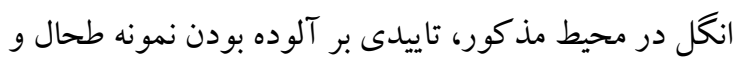

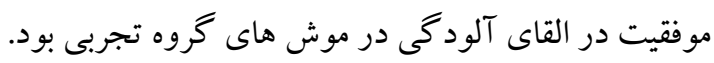

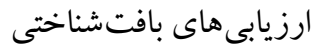

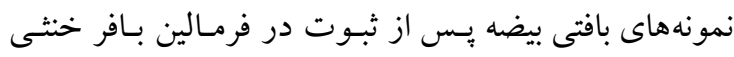

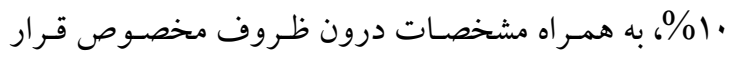
كر فتند و بعد از طى مر احل بـاساز بافتى با استفاده از يـارافين

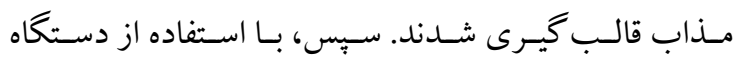

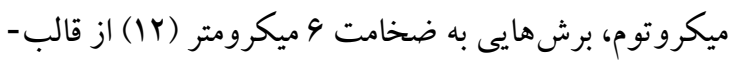

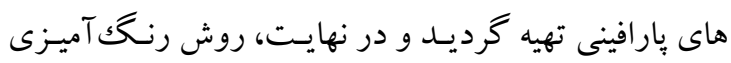

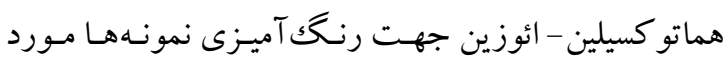

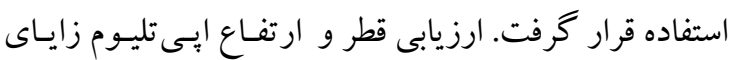
لولههاى اسبرمساز بيضه در گروههاى آزمايشى با استفاده از از

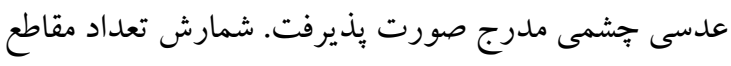

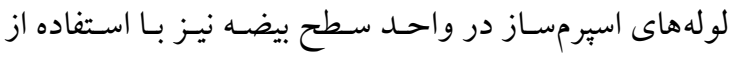

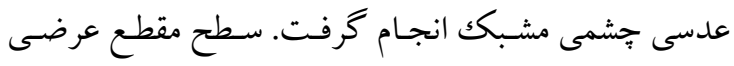

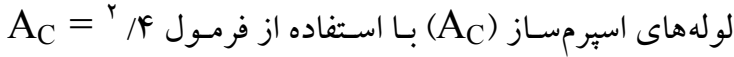

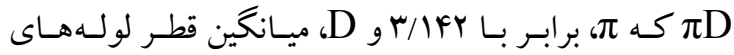

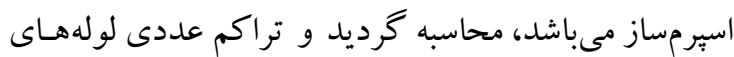
$N_{V}=N_{A} /(D+T)$ بـر اساس معادله

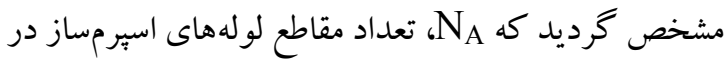


جدول ا: مقايسه ميانگين يافتهاى بافتشناسى در گروههاى آزمايشى

\begin{tabular}{|c|c|c|c|}
\hline & كروه شاهد & ليشمانياز احشايى تجربى & $P$ value \\
\hline $\mathrm{STsD}(\mu \mathrm{m})$ & $1 / r a \pm 1 \Delta V / F r$ & $\cdot / V F \pm q r / V q$ & $\cdot / \cdot$ \\
\hline GEH $(\mu \mathrm{m})$ & $1 / 4 A \pm 99 / Y F$ & $1 / 4 q \pm r r / 9 \Lambda$ & $\%$ \\
\hline JS & $\cdot / / Y \pm \Lambda / \Lambda$. & $\cdot / 19 \pm \Delta / Y r$ & $\%$ \\
\hline MSTs & $1 / \cdot r \pm V r / 9 r$ & $r / Q 1 \pm r \Delta / \Delta \Lambda$ &.$/$ \\
\hline $\mathrm{N}_{\mathrm{A}}$ & $\cdot / V V \pm r V / l$ & $\cdot / V 9 \pm 19 / 1 \Lambda$ &.$/$ \\
\hline $\mathrm{N}_{\mathrm{V}}$ & $\cdot / r Y \pm I V / r q$ & $\cdot / \Delta 1 \pm 19 / A r$ &.$/ 1 \Lambda$ \\
\hline $\mathrm{A}_{\mathrm{C}}$ & $\cdot / r V \pm 19 / 99$ & $\cdot / 1 \cdot \pm 9 / 19$ &.$/ \cdot$ \\
\hline
\end{tabular}

هييوسلولاريته، از هم گسيختكى ايى تليوم زايا و توقف بلوغ همراه با تجمع سلولهاى اسيرماتوزنيكك در حفره ميانى لوله هاى اسيرمساز در گروه تجربى نشـان داد (شكل B-1)

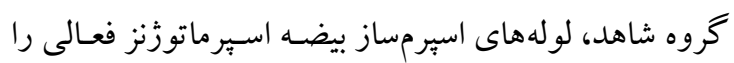

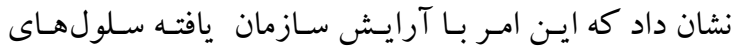
اسيرماتوزنيكك در مراحل مختلف بلـوغ در ايسىتليـوم زايـاى لوله هاى اسبرمساز بيضه همر اه بود (شكل A-A (1).
STsD قطر لولهاى اسبرمساز بيضه؛ GEH: : ارتفـاع ايسى : تليوم زاياى لوله هاى اسِرمساز بيضه؛ JS : شاخص جانسـ؛ MSTs لوله لهاى اسبرمساز در واحد سطح بيضه؛ NV: تراكم عـددى لولههاى اسبرمساز بيضه؛ AC: سطح مقطع عرضى لولـههـاى

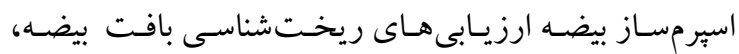

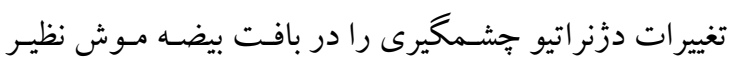

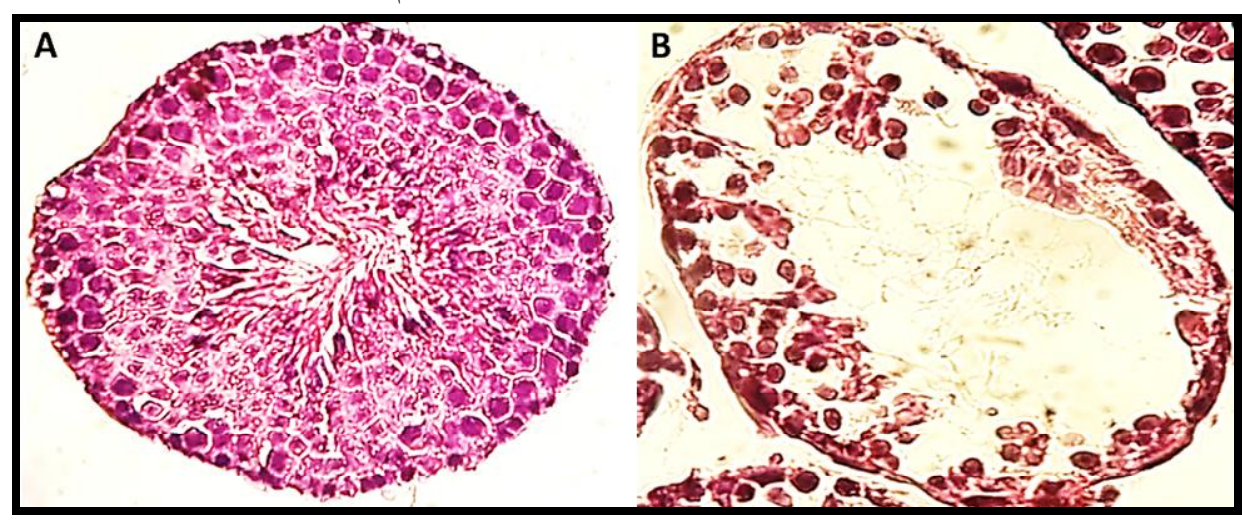

شكل ا: برش عرضى از لوله اسِرمساز بيضه: در گروه شاهد (A)، لوله اسبرمساز بيضه موش واجد نماى بافتشناختى طبيعى مسىباشـد و اسـبرماتوزنز

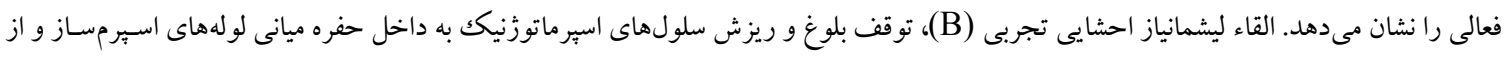

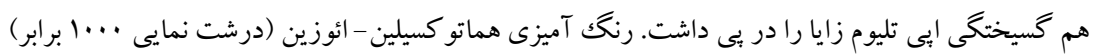


در موش همخوانى دارد. همجنـين، در تاييـد يافتـهــاى مطالعـه حاضر، تحقيقات متعدد صورت گرفته نشـان داده اسـت كـه

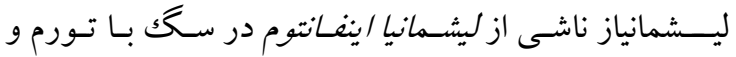
آسـيب بيضـه و اييديـديم (11) و اخستلالات اسـيرمى نظيـر كاهش ميزان تحرك و افزايش نقـائص مورفولوزيـك (YY)

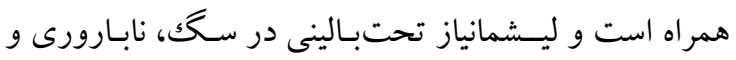
تورم يروستات مزمن را در يى خو اهد داشت (سب). مكانيسم دقيق نابارورى و اختلالات توليدمثلى ناشسى از ايـن آلود گحىهاى به روشنى معلوم نيست و نيـاز بـه مطالعـه بيشـتر دارد. با اين وجود، مطالعات بيشين بر نقـش ارتشـاح سـلولهاى آماسى و افزايش توليد سيتو كينهاى ييش التهابى نظير اينترفرون كاما و فاكتور نكروز دهنـده تومـور آلفـا در بـروز

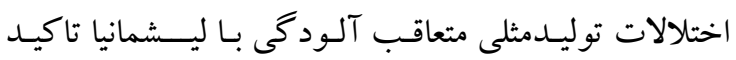
دارند (YF، YO). از سوى ديخر، به خوبى مشخص شـده اسـت كه شكل گيرى ياسخ هاى ايمنى و نفوذ سـلول هـاى ايمنى در بافت يضه، زمينه تغيير نفوذيذيرى سد خـونى -بيضـهاى، توليـد آنتـىبـادىهـاى ضداسـيرم، تغيــرات عروقى، افـزايش وقـوع آيويتوز در سلولهاى زايا و بروز تسنش اكسـيداتيو را فراهم مى آورد كه با تغييـرات مشـهود سـاختار بـافتى بيضـه همـر اه

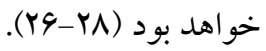
به علاوه، پِارازيتمى انخل نيز ممكن است بـه واسـطه انسـداد عروق خونى بيش و ي-سمـويركى بافـت بيضـه، اخـتلال در خونرسانى و هيبو كسى بافتى را موجب گـردد و زمينـهساز آتروفى، تغييرات دزنر اتيو و مرگك سـلولهـاى زايـاى بافـت بيضه گردد (Yq) و از طرفى، با توجه به اين كه در آلود گحى به ليشـمانيا احشـايى، درگيـرى دستخاه رتيكولوانـدوتليال و تخريب سلول هاى ماكروفاز اتفاق مى افتد، بهتدريج طحسال و بافت مغز استخوان بيشترين بافت تحت تـاثير مسىباشـندكه بخش خونساز بدن را نيز به عهده دارند و تراكم شديد انگل در اين بافتها رخ مسىدهـد كـه تخريـب بـافتى و عـوارض مختلف را همر اه دارد و اختلالات ناشى از آن، خود به خود

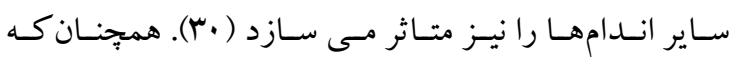

ليشمانيازيس با اهميت بهداشتى جهانى، يكى از بيماريهاى مشتر كك بين انسان وحيوان مىباشدكه بـه سـه شـكل جلــى (سالكs)، احشايى (كالازار ) و جلدى مخاطى بروزمى كنـد.

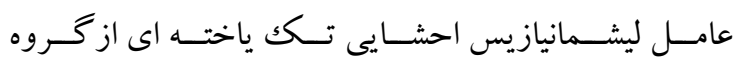
تاز كداران، خانواده ترييانوزماتيـده و وجـنس ليشـمانيا (كونـه

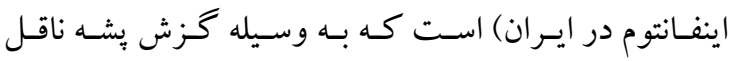
ازخــانو اده يسـيكوديده، زيرخــانو اده فلبوتومينــه ازمخــازن

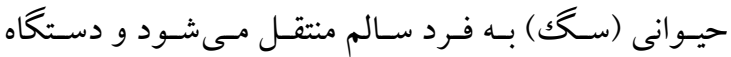

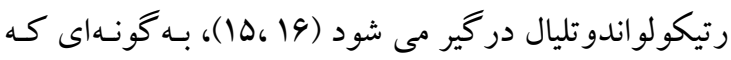
به تدريج با انتشار آن در بدن، احشاء و اندامهـاى مختلـف را مى تواند تحت تاثير قرار دهد و بسته به محل در گيرى علائم آن متفاوت اسـت. از جملـه انـدامهـاى درگيــ مسى تـوان بـهـ دستخاه توليدمثلى اشاره داشت و به واسطه اخـتلال عملكـرد دستگاه توليدمثلى مى تواند موجبات نابارورى را فراهم آورد (IV) (IV) ليـشمانياز احسشايى نيـز قـادر بـه ايجـاد عـوارض نـامطلوب توليدمثلى در انسان و حيوانات مىباشد ( •Y-N). يافتهـهـاى مطالعـه حاضـر كـه در راستاى ارزيـابى تغييـرات استريولوزيكك، مورفومتريك و ريختشناسى سـاختار بـافتى بيضه در ليشمانياز احشايى تجربى ناشى از ليشـمانيا /ينغـانتوم در موشهاى BALB/c طرحريزى گرديده بـود نشـان داد كه ليشمانياز احشايى تجربى تغييرات دزنراتيو قابلملاحظه اى را دربافت بيضه موش هاى BALB/c موجب مى گر دد كـه ايسن امـر بـه صـورت كـاهش قابـل توجـه فراسـنجه هـاى استريولوزيكى و مورفومتريكك به عنوان شاخصهاى ارزيابى ميز ان آسيب بافتى نمود بيدا مى كند ( (Y). مطالعات صـورت كرفته نشان داده است كـه كـه آلودگى تجربسى بـاليشـمانيا دونووانى در هامستر بـا آتروفى بيشـرفته بافت بيضـه و نيـز آزوسيرمى شديد همراه است (9) كـه ايسن گَزارش بـانتـايج حاصل از ارزيابىهاى بافتشناختى مطالعه حاضر مبنى بـر نقـش ليسشمانياز احسشايى تجربى در بروز اختلالات اسيرماتوزنيك

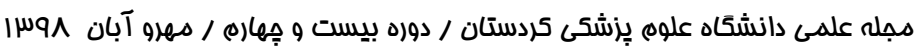




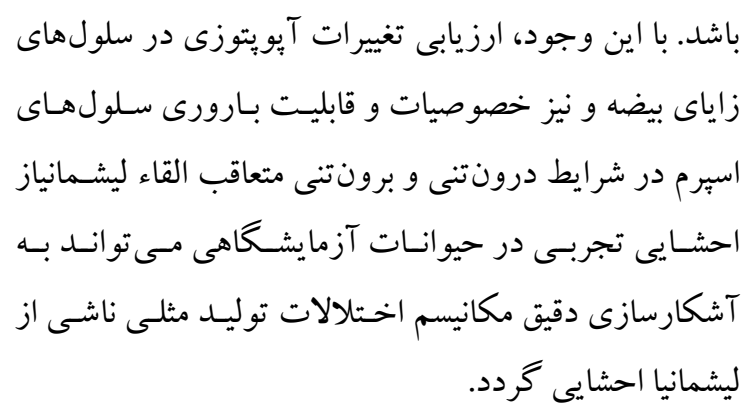

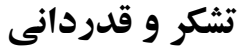

نويسند كان اين مقاله مراتب تشكر خود را از از دانشعاه علدوم

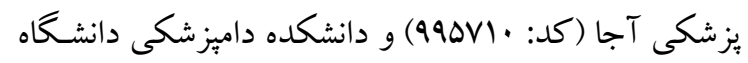

$$
\text { اروميه ابراز مى دارند. }
$$

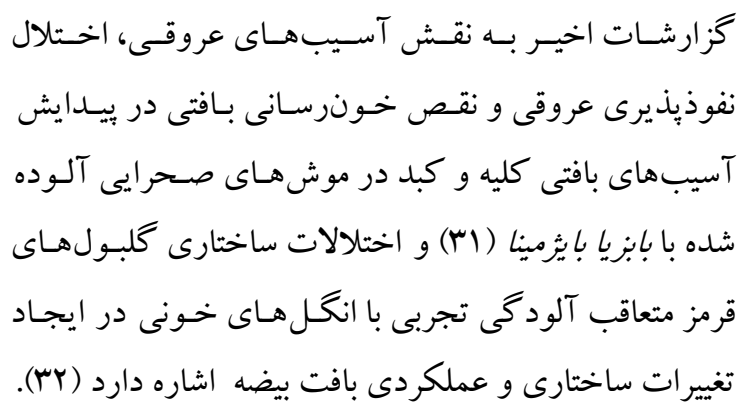

\section{نتيجه كيرى}

در ايسن مطالـه، ليشـمانياز احشـايى تجربسى تخريسب هـاى مشخص بافتى در موشهـاى BALB/c مـورد آزمايش را

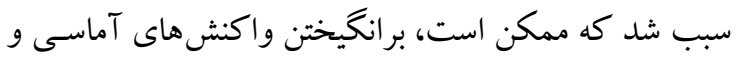
زمينهسازى نفوذ سلولهاى ايمنى، تغييرات عروقى، تخريـب بافت مغزاستخو ان و طحال منجر به جراحات بافتى بيضه شده

\section{References}

1. Desjeux P. Worldwide increasing risk factors for leishmaniasis. Med Microbiol Immunol 2001;190:77-9.

2. Desjeux P. Leishmaniasis: current situation and new perspectives. Comp Immunol Microbiol Infect Dis 2004;27:305-18.

3. Palatnik-de-Sousa CB, Day MJ. One health: the global challenge of epidemic and endemic leishmaniasis. Parasit Vectors 2011;4:197.

4. Ashford RW. The leishmaniases as emerging and reemerging zoonoses. Int $\mathrm{J}$ Parasitol 2000;30:1269-81.

5. Mohebali M, Hajjaran H, Hamzavi Y, Mobedi I, Arshi S, Zarei Z, et al. Epidemiological aspects of canine visceral leishmaniosis in the Islamic Republic of Iran. Vet Parasitol 2005; 129:243-51.

6. Fakhar M, Rahmati B, Gohardehi S, Mohebali M, Akhoundi B, Sharif M, et al. Molecular and seroepidemiological survey of visceral leishmaniasis among humans and domestic dogs in Mazandaran Province, North of Iran. Iran J Parasitol 2011;6:51-9.

7. Weina PJ, Neafie RC, Wortmann G, Polnemus M, Aronson NE. Old world leishmaniasis: an emerging infection among deployed US military and civilian workers. Clin Infect Dis 2004;39:1674-80.

8. Claborn D, Masaouka P, Morrow M, Kee PL. Habitat analysis of North American sand flies near veterans returning from leishmania-endemic war zones. Int J Health Geogr 2008;7: 65.

9. Gonzalez JL, Gallego E, Castaño M, Rueda A. Testicular amyloidosis in hamsters experimentally infected with Leishmania donovani. Br J Exp Pathol 1983;64:518-23.

10. Sharma M, Kaur S. Histological evaluation of cisplatin-induced gonadotoxicity against murine visceral leishmaniasis. Glob J Curr Res 2013;1:27-30. 
11. Manna L, Paciello O, Morte RD, Gravino AE. Detection of Leishmania parasites in the testis of a dog affected by orchitis: case report. Parasit Vectors 2012;5:216.

12. Jalali AS, Hasanzadeh S, Malekinejad H. Achillea millefolium inflorescence aqueous extract ameliorates cyclophosphamide-induced toxicity in rat testis: stereological evidences. Chin J Nat Med 2012;10: 247-54.

13. Johnsen SG. Testicular biopsy score count - a method for registration of spermatogenesis in human testes: normal values and results in 335 hypogonadal males. Hormones 1970;1:225.

14. Ghasemi FM, Faghani M, Khajehjahromi S, Bahadori M, Nasiri E, Hemadi M. Effect of melatonin on proliferative activity and apoptosis in spermatogenic cells in mouse under chemotherapy. J Reprod Contracept. 2010;21:79-94.

15. Shaddel M, Sharifi I, Karvar M, Keyhani A, Baziar Z. Cryotherapy of cutaneous leishmaniasis caused by Leishmania major in BALB/c mice: A comparative experimental study. $J$ Vector Borne Dis 2018;55:42-6.

16. Shaddel M, Oormazdi H, Akhlaghi L, Kazemi B, Bandehpour M, Cloning of Leishmania major p4 gene YAKHTEH. 2008;10:201-4.

17. Shiadeh MN, Niyyati M, Fallahi S, Rostami A. Human parasitic protozoan infection to infertility: a systematic review. Parasitol Res 2016;115:469-77.

18. Cabello I, Caraballo A, MillanY. Leishmaniasis in the genital area. Rev Inst Med Trop Sao Paulo. 2002;44:105-7.

19. Blickstein I, Dgani R, Lifschitz-Mercer B. Cutaneous leishmaniasis of the vulva. Int J Gynaecol Obstet 1993;42:46-7.

20. Coto ACHH, Aguilar ES. Leishmaniasis in male genital organs. Med Cut ILA 1987;15: $145-50$.

21. Yurtcu M, Abasiyanik A, Biçer S, Avunduk MC. Efficacy of antioxidant treatment in the prevention of testicular atrophy in experimental testicular torsion. J Pediatr Surg 2009;44: 1754-8.

22. Assis VP, Ribeiro VM, Rachid MA, Castro AC, Valle GR. Dogs with Leishmania chagasi infection have semen abnormalities that partially revert during 150 days of allopurinol and amphotericin B therapy. Anim Reprod Sci 2010;117:183-6.

23. Mir F, Fontaine E, Reyes-Gomez E, Carlus M, Fontbonne A. Subclinical leishmaniasis associated with infertility and chronic prostatitis in a dog. J Small Anim Pract 2012;53:41922.

24. Diniz SA, Melo MS, Borges AM, Bueno R, Reis BP, Tafuri WL, et al. Genital lesions associated with visceral leishmaniasis and shedding of Leishmania $\mathrm{sp}$. in the semen of naturally infected dogs. Vet Pathol 2005; 42:650-8.

25. Krishnan L, Guilbert LJ, Wegmann TG, Belosevic M, Mosmann TR. T helper 1 response against Leishmania major in pregnant C57BL/6 mice increases implantation failure and fetal resorptions. Correlation with increased IFN-gamma and TNF and reduced IL-10 production by placental cells. J Immunol 1996;156:653-62.

26. Guazzone VA, Jacobo P, Theas MS, Lustig L. Cytokines and chemokines in testicular inflammation: a brief review. Microsc Res Tech 2009;72:620-8.

27. Lysiak JJ, Nguyen QA, Kirby JL, Turner TT. Ischemia-reperfusion of the murine testis stimulates the expression of proinflammatory cytokines and activation of c-jun N-terminal kinase in a pathway to E-selectin expression. Biol Reprod 2003;69:202-10.

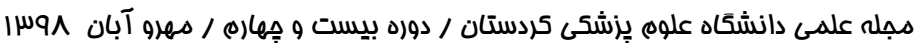


28. Hedger MP, Meinhardt A. Cytokines and the immune-testicular axis. J Reprod Immunol 2003;58:1-26.

29. Paraguai de Souza E, Esteves Pereira AP, Machado FC, Melo MF, Souto-Padrón T, Palatnik M, et al. Occurrence of Leishmania donovani parasitemia in plasma of infected hamsters. Acta Trop 2001;80:69-75.

30. Noronha TR, Fock RA. Visceral leishmaniasis: amastigotes in the bone marrow. Hematol Transfus Cell Ther 2019;41:99-100.

31. Hamoda AF, Radwan M, Rashed R, Amin A. Toxic effect of babesiosis in cattle and chemotherapeutic treatment in Egypt. Am J Infect Dis Microbiol 2014;2:91-6.

32. Shamaei-Tousi A, Collin O, Bergh A, Bergström S. Testicular damage by microcirculatory disruption and colonization of an immune-privileged site during Borrelia crocidurae infection. J Exp Med 2001;193:995-1004. 